Research Paper

\title{
Effectiveness of halo-tolerant, auxin producing Pseudomonas and Rhizobium strains to improve osmotic stress tolerance in mung bean (Vigna radiata L.)
}

\author{
Maqshoof Ahmad ${ }^{1,2}$, Zahir A. Zahir ${ }^{1}$, Farheen Nazli ${ }^{3}$, Fareeha Akram ${ }^{1}$, Muhammad \\ Arshad $^{1}$, Muhammad Khalid ${ }^{1}$ \\ ${ }^{1}$ Institute of Soil and Environmental Sciences, University of Agriculture, Faisalabad, Pakistan. \\ ${ }^{2}$ University College of Agriculture and Environmental Sciences, \\ The Islamia University of Bahawalpur, Bahawalpur, Pakistan. \\ ${ }^{3}$ Pesticide Quality Control Laboratory, Bahawalpur, Pakistan.
}

Submitted: July 21, 2012; Approved: April 4, 2013.

\begin{abstract}
Halo-tolerant, auxin producing bacteria could be used to induce salt tolerance in plants. A number of Rhizobium and auxin producing rhizobacterial strains were assessed for their ability to tolerate salt stress by conducting osmoadaptation assay. The selected strains were further screened for their ability to induce osmotic stress tolerance in mung bean seedlings under salt-stressed axenic conditions in growth pouch/jar trials. Three most effective strains of Rhizobium and Pseudomonas containing ACC-deaminase were evaluated in combination, for their ability to induce osmotic stress tolerance in mung bean at original, 4 , and $6 \mathrm{dS} \mathrm{m}^{-1}$ under axenic conditions. Results showed that sole inoculation of Rhizobium and Pseudomonas strains improved the total dry matter up to 1.4, and 1.9 fold, respectively, while the increase in salt tolerance index was improved up to 1.3 and 2.0 fold by the Rhizobium and Pseudomonas strains, respectively. However, up to 2.2 fold increase in total dry matter and salt tolerance index was observed due to combined inoculation of Rhizobium and Pseudomonas strains. So, combined application of Rhizobium and Pseudomonas strains could be explored as an effective strategy to induce osmotic stress tolerance in mung bean.
\end{abstract}

Key words: ACC-deaminase, Pseudomonas, Rhizobium, osmotic stress, salt tolerance index.

\section{Introduction}

Salinity is one of the major yield limiting factors World wide that hinders plant growth by affecting a number of physiological processes positively or negatively. It is a serious production problem for crops as saline conditions are known to suppress plant growth, particularly in arid and semiarid regions (Parida and Das, 2005). Increased salinity in the rhizosphere decreases the osmotic potential of the root zone soil solution (Chartzoulakis et al., 2002) resulting in reduced availability of water to plants. Salinity stress adversely affects total dry matter and plant growth as most part of the energy is used in making osmotic adjustments by the plant (Munns and Termaat, 1986). Increased production of ethylene due to exogenous application of 1-aminocyclopropane-1-carboxylic acid (ACC) or salinity can decrease root growth (Madhaiyan et al., 2007) and consequently growth of the plant.

The ethylene which is produced in excess due to salinity may be controlled by a number of chemical and biological approaches. However, in most cases, chemical approach may become expensive, less feasible or potentially harmful to the environment. The use of rhizobacteria containing ACC-deaminase becomes one of the most widely acceptable approaches to reduce the effect of stress-induced ethylene on plants. These plant growth promoting rhizobacteria (PGPR) contain an enzyme ACCdeaminase which hydrolyzes ACC (immediate precursor of ethylene) into ammonia and $\alpha$-ketobutyrate (Mayak et al., 1999; Tahir et al., 2006). These PGPR boost the plant growth, particularly under stressed conditions, by the regulation of accelerated ethylene production in response to a

Send correspondence to M. Ahmad. Institute of Soil and Environmental Sciences, University of Agriculture, Faisalabad-38040, Pakistan. E-mail: maqshoof_ahmad@yahoo.com. 
multitude of abiotic and biotic stresses (Belimov et al., 2009a, 2009b). The increase in growth of plants under normal conditions has been reported due to inoculation with Indole acetic acid (IAA) producing bacteria (Malhotra and Srivastava, 2006). As IAA plays a vital role to induce salinity tolerance in plans (Azooz et al., 2004) hence, the use of auxin producing PGPR containing ACC deaminase activity may be more economical, environmental friendly and feasible in a natural soil and plant system.

Bacterial strains have variable ability to tolerate the salt stress (Lloret et al., 1995) and some salt tolerant Rhizobium strains can grow at $\mathrm{NaCl}$ concentration up to $500 \mathrm{mM}$. The salt-tolerant rhizobia go through some morphological, metabolic and structural modifications to muddle through the salt stress. Higher salt tolerance by bacterial strains was also reported by Mensah et al. (2006) and Sgroy et al. (2009). Similarly, Hafeezet al. (1988) reported that most of the Rhizobium strains were salt tolerant and performed better for growth promotion of Vigna radiata under salt-stressed conditions. So, it is imperative to screen indigenous strains of rhizobia that are more efficient to fix atmospheric nitrogen under stressed conditions (Woldeyohannes et al., 2007).

Co-inoculation of legumes with Pseudomonas sp. and rhizobia has also been reported to stimulate plant growth by affecting some physiological functions (Derylo and Skorupska, 1993; Dashti et al., 1997). It improves plant growth by reduction in ethylene level (Shaharoona et al., 2006), direct stimulation of rhizobial growth/survival in the soil, enlargement of the root system by hormone production for enhanced nutrient uptake and increase in the number of potential colonization sites by Rhizobium (Gull et al., 2004; Barea et al., 2005). So, the present study was conducted to screen the auxin producing, halo-tolerant Rhizobium and Pseudomonas strains for improving osmotic stress tolerance index in mung bean.

\section{Materials and Methods}

\section{Collection of bacterial strains}

Twenty five strains of rhizobacteria and ten Rhizobium strains were isolated from rhizosphere and nodules of mung bean growing in salt-affected fields. The Rhizobium strains were coded as M1-M10 and rhizobacterial strains as Mk1-Mk25 (Ahmad et al., 2011).

\section{ACC-metabolism assay (Qualitative)}

The ability of rhizobacteria to utilize ACC as sole nitrogen source was assayed qualitatively as described by Jacobson et al. (1994).

\section{Auxin production assay}

Auxin production by the rhizobacterial strains in the presence and absence of L-tryptophan was estimated by us- ing colorimetric method in terms of IAA equivalents by following the method of Sarwar et al. (1992).

\section{Osmoadaptation assay}

Osmoadaptation assay of rhizobial and rhizobacterial strains was carried out as described by Zahir et al. (2010), to assess their salinity tolerance at original, 4,8 and $12 \mathrm{dS} \mathrm{m}^{-1}$ salinity levels. Four salinity levels i.e. original, 4 , 8 and $12 \mathrm{dS} \mathrm{m}^{-1}$ were developed in yeast extract mannitol (YEM) and general purpose media (GPM) for rhizobial and rhizobacterial strains, respectively. Fifteen milliliters of the respective broth were taken in test tubes. The sterilized broth in tubes were inoculated with the uniform population of the respective rhizobial or rhizobacterial strains $\left(\mathrm{OD}_{540}=0.3\right)$. Tubes were incubated at $28 \pm 1{ }^{\circ} \mathrm{C}$ and absorbance was measured by using spectrophotometer at $540 \mathrm{~nm}$ wavelengths after 3 days of incubation.

\section{Preparation of inocula for osmoadaptation and pouch trials}

Inocula were prepared in flasks by using YEM and DF minimal salt medium containing ACC as substrate (N source), without agar for rhizobial and rhizobacterial strains, respectively. Each flask containing broth was inoculated with respective strains of rhizobia or rhizobacteria and incubated at $28 \pm 1{ }^{\circ} \mathrm{C}$ for 72 hours under shaking (100 rpm) conditions. After incubation, optical density was measured and uniform population $\left(\mathrm{OD}_{540}=0.45 ; 10^{7}\right.$ $10^{8} \mathrm{cfu} \mathrm{mL}^{-1}$ ) was achieved by dilution with sterilized water prior to seed inoculation.

\section{Screening of rhizobacterial and rhizobial strains for inducing osmotic stress tolerance}

The growth pouch and jar experiments were conducted in growth room for the screening of rhizobacteria and Rhizobium, respectively, under gnotobiotic conditions. Broths were prepared by DF minimal salt medium containing ACC as substrate and YEM medium for rhizobacteria and Rhizobium, respectively, as described earlier.

Mung bean seeds were surface-sterilized by dipping in $95 \%$ ethanol for few moments followed by $0.2 \% \mathrm{HgCl}_{2}$ solution for three minuets, and thoroughly washing with sterilized water. Three surface-sterilized seeds were dipped in the respective inocula of rhizobacteria or Rhizobium (prepared as described above) for ten minutes and placed in the autoclaved growth pouches (MEGA-International, West St. Paul, USA) or jars for rhizobacteria and Rhizobium, respectively. Sterilized broths were used for the control treatment. Each treatment was replicated thrice. Three salinity levels (original, 4 and $6 \mathrm{dS} \mathrm{m}^{-1}$ ) were maintained by using $\mathrm{NaCl}$ in sterilized Hoagland solution $(1 / 2$ strength) and modified N-free, Hoagland solution for rhizobacteria and Rhizobium, respectively, (Fahraeus, 1957). In the growth room, the temperature was maintained at $28 \pm$ $1{ }^{\circ} \mathrm{C}$ and 10 hours of light $\left(275 \mu \mathrm{mol} \mathrm{m}^{-2} \mathrm{~s}^{-1}\right)$ alternated with 
14 hours darkness. The rhizobacterial inoculated trial was harvested after 21 days while the Rhizobium inoculated trial was harvested after 60 days and data regarding seedlings growth were recorded.

\section{Identification of selected strains}

The selected rhizobacterial strains were identified by using the $\mathrm{BIOLOG}^{\circledR}$ identification system (Microlog System release 4.2 Biolog Inc., USA). The Biolog ${ }^{\circledR}$ identification system has been found equally as reliable for identification as 16s RNA (Flores-Vargas and O, Hara, 2006). The rhizobacterial strains were Pseudomonas syringae, (Mk1); Pseudomonas fluorescens, (Mk20) and Pseudomonas fluorescens Biotype G, (Mk25). The similarity values obtained from the Biolog assay were 94, 89 and $88 \%$ for Pseudomonas syringae, (Mk1); Pseudomonas fluorescens, (Mk20) and Pseudomonas fluorescens Biotype G, (Mk25), respectively. The confirmation of the Rhizobium strains was carried out by isolation of the Rhizobium from the nodules of mung bean and upon re-inoculation these strains nodulated the mung bean seedlings (Ahmad et al., 2011).

\section{Screening of effective combinations of Rhizobium and Pseudomonas strains containing ACC-deaminase for inducing osmotic stress tolerance}

Screening of effective (Pseudomonas x Rhizobium) combinations was carried out under gnotobiotic conditions in the growth room. Broth cultures of selected Rhizobium and Pseudomonas strains were prepared as described earlier.

For co-inoculation, broth cultures of Pseudomonas strains and Rhizobium were used in the 1:1 ratio. Surface-sterilized mung bean seeds were dipped in this combined broth for ten minutes. Three co-inoculated seeds were sown in autoclaved growth pouches. In case of control, sterilized broths were used for seed dipping. Each treatment was replicated thrice. Three salinity levels [original (1.62), 4 and $6 \mathrm{dS} \mathrm{m}^{-1}$ ] were maintained by using $\mathrm{NaCl}$ in sterilized Hoagland solution ( $1 / 2$ strength). The temperature in the growth room was adjusted to $28 \pm 1{ }^{\circ} \mathrm{C}$ with 10 hours of light $\left(275 \mu \mathrm{mol} \mathrm{m} \mathrm{s}^{-1}\right)$ and 14 hours dark period. Data regarding seedlings growth were recorded.

The experiments were conducted in the growth room and all operations were carried out aseptically in a Laminar flow-hood.

\section{Salt tolerance index}

Effect of bacterial inoculation on mung bean was calculated by taking the salt tolerance indices of inoculated and un-inoculated plants grown under stress and normal conditions according to Shetty et al. (1995) as:

$$
\text { Salt tolerance index }(\mathrm{STI})=\frac{\text { DWS or DWI }}{\text { DWC }}
$$

where DWS = dry weight of stressed plants, DWI = dry weight of inoculated plants and DWC $=$ dry weight of un-stressed and un-inoculated control.

\section{Statistical analysis}

Analysis of variance techniques (ANOVA) were applied to analyze the data (Steel et al., 1997) using completely randomized design and means were compared by Duncan's Multiple Range Test (Duncan, 1955).

\section{Results}

\section{ACC metabolism assay for rhizobacterial strains}

The rhizobacterial strains were screened for their ability to utilize ACC as a sole source of nitrogen and for this purpose a qualitative ACC metabolism assay was performed. The results of the bioassay showed that all the rhizobacterial strains had the ability to utilize ACC as a sole source of nitrogen but with variable degree of efficacy. So, all these strains possessed ACC-deaminase activity. On the basis of growth [optical density values at $540 \mathrm{~nm}\left(\mathrm{OD}_{540}\right)$ ], these strains were grouped into low, medium and high ACC utilizing strains (Table 1).

Out of twenty five strains, seven strains having the maximum ACC utilization were grouped as high ACC utilizing strains $\left(\mathrm{OD}_{540}>0.75\right)$, ten strains having medium growth $\left(\mathrm{OD}_{540}: 0.50-0.75\right)$ were grouped as medium ACC utilizing strains and the remaining having less growth i.e. $\mathrm{OD}_{540}<0.50$ were grouped as low ACC utilizing strains.

On the basis of the results of ACC metabolism assay, ten strains having maximum cell growth on ACC substrate were selected for further experimentation.

Table 1 - Cell growth $\left(\mathrm{OD}_{540}\right)$ of the rhizobacteria on ACC substrate (Average of three replicates $\pm \mathrm{SE}$ ).

\begin{tabular}{lccc}
\hline Code name & OD Value & Code name & OD Value \\
\hline Mk1* & $0.76 \pm 0.03$ & Mk14 & $0.41 \pm 0.02$ \\
Mk2 & $0.59 \pm 0.02$ & Mk15* & $0.71 \pm 0.03$ \\
Mk3* & $0.95 \pm 0.02$ & Mk16 & $0.61 \pm 0.02$ \\
Mk4 & $0.43 \pm 0.02$ & Mk17 & $0.37 \pm 0.03$ \\
Mk5* & $0.63 \pm 0.03$ & Mk18 & $0.47 \pm 0.02$ \\
Mk6 & $0.49 \pm 0.03$ & Mk19 & $0.55 \pm 0.03$ \\
Mk7 & $0.047 \pm 0.02$ & Mk20* & $0.79 \pm 0.03$ \\
Mk8* & $0.61 \pm 0.02$ & Mk21 & $0.31 \pm 0.03$ \\
Mk9 & $0.60 \pm 0.03$ & Mk22* & $0.75 \pm 0.04$ \\
Mk10* & $0.77 \pm 0.01$ & Mk23 & $0.51 \pm 0.02$ \\
Mk11 & $0.44 \pm 0.02$ & Mk24 & $0.55 \pm 0.03$ \\
Mk12 & $0.53 \pm 0.01$ & Mk25* & $0.91 \pm 0.02$ \\
Mk13* & $0.77 \pm 0.02$ & & \\
\hline
\end{tabular}

*Strains selected for further experimentation. 


\section{Auxin production by rhizobacterial strains}

The results of the auxin production assay (Table 2) showed that all rhizobacterial strains produced auxins measured in terms of IAA equivalents in the presence and absence of L-TRP but they varied in their ability to produce auxin. In the absence of L-TRP, the maximum auxin was produced by the strain Mk25 which gave significantly different results compared with control as well as other strains. While in the presence of L-TRP, the strains Mk20 and Mk25 were equally effective to produce auxin, and they were statistically different from control and other strains.

\section{Osmoadaptation assay}

Salt tolerance of selected rhizobacterial strains containing ACC-deaminase and Rhizobium was assessed by conducting osmoadaptation assay. The Rhizobium and rhizobacterial strains were grown at four salinity levels i.e. original, 4,8 and $12 \mathrm{dS} \mathrm{m}^{-1}$ and the optical density was measured. The results showed that the bacterial strains varied in their ability to tolerate the salt-stressed conditions.

\section{Osmoadaptation assay for rhizobacterial strains}

To assess salt tolerance of rhizobacterial strains, these were grown at four salinity levels i.e. original (1.59), 4, 8 and $12 \mathrm{dS} \mathrm{m}^{-1}$. The growth of strains (OD at $540 \mathrm{~nm}$ ) was measured after 3 days of incubation. The results of the study revealed that growth of rhizobacterial strains decreased with increasing level of salinity and the strains varied in their ability to tolerate the higher level of salinity. At higher salinity level $\left(12 \mathrm{dS} \mathrm{m}^{-1}\right)$, the maximum optical density was observed in case of strain Mk25 followed by Mk1, Mk8, and Mk20 (Table 3).

Table 2 - Auxin production (IAA equivalents) by rhizobacterial strains in the presence and absence of L-TRP.

\begin{tabular}{lcc}
\hline \multirow{2}{*}{ Strain } & \multicolumn{2}{c}{ IAA production $\left(\mathrm{mg} \mathrm{L}^{-1}\right)$} \\
\cline { 2 - 3 } & Without L- TRP & With L-TRP \\
\hline Mk1 & $6.89 \mathrm{~d}$ & $9.26 \mathrm{~b}$ \\
Mk3 & $3.26 \mathrm{e}$ & $9.47 \mathrm{~b}$ \\
Mk5 & $1.90 \mathrm{f}$ & $6.09 \mathrm{c}$ \\
Mk8 & $8.20 \mathrm{bc}$ & $11.42 \mathrm{a}$ \\
Mk10 & $6.70 \mathrm{~d}$ & $11.66 \mathrm{a}$ \\
Mk13 & $6.88 \mathrm{~d}$ & $9.76 \mathrm{~b}$ \\
Mk15 & $6.56 \mathrm{~d}$ & $10.35 \mathrm{~b}$ \\
Mk20 & $9.64 \mathrm{a}$ & $12.41 \mathrm{a}$ \\
Mk22 & $7.61 \mathrm{c}$ & $11.66 \mathrm{a}$ \\
Mk25 & $8.51 \mathrm{~b}$ & $12.43 \mathrm{a}$ \\
LSD $(\mathrm{p}<0.05)$ & 0.6432 & 1.0626 \\
\hline
\end{tabular}

Means sharing same letters are statistically at par at $5 \%$ level of probability. $\mathrm{n}=3$.

\section{Osmoadaptation assay for Rhizobium strains}

The results (Table 4) of the osmoadaptation assay for Rhizobium strains showed that salinity stress had negative effect on the growth (cell density) of Rhizobium strains and the growth of these strains decreased with increasing level of salinity. But all the strains had variable growth at all salinity levels. Under normal conditions, the maximum cell density was observed by the strains M10. At $12 \mathrm{dS} \mathrm{m}^{-1}$, maximum growth was observed in the case of M9 strain.

\section{Screening of rhizobacteria and Rhizobium strains for} inducing osmotic stress tolerance

The rhizobacteria containing ACC-deaminase activity and Rhizobium were screened for their ability to improve osmotic stress tolerance in mung bean under axenic conditions. The results imply that the salinity significantly reduced the total dry matter and salt tolerance index of mung bean seedlings but the inoculation with rhizobacteria containing ACC-deaminase and Rhizobium, significantly reduced the inhibitory effects of salinity and improved the total dry matter and salt tolerance index of mung bean seedlings.

Data (Table 5) showed that all the strains of rhizobacteria containing ACC-deaminase showed non-significant increase in total dry matter of mung bean seedlings except Mk1 which was statistically significant over un-inoculated control and it increased total dry matter the up to 1.4 fold over the un-inoculated control, at higher salinity level. Inoculation with Rhizobium also reduced the inhibitory effect of salinity with different degrees of efficacy (Table 6). Under original salinity level, maximum increase in total dry matter over the un-inoculated control was $192 \%$ with Rhizobium strain M6. At $6 \mathrm{dS} \mathrm{m}^{-1}$, all the strains showed non-significant results with un-inoculated control, how-

Table 3 - Response of rhizobacterial strains to different levels of salinity after 3 days of incubation.

\begin{tabular}{lcccc}
\hline Strain & \multicolumn{5}{c}{ Optical density at $540 \mathrm{~nm}$} \\
\cline { 2 - 5 } & $1.59 \mathrm{dS} \mathrm{m}^{-1}$ & $4 \mathrm{dS} \mathrm{m}^{-1}$ & $8 \mathrm{dS} \mathrm{m}^{-1}$ & $12 \mathrm{dS} \mathrm{m}^{-1}$ \\
\hline Mk1 & $0.623 \mathrm{~b}-\mathrm{f}$ & $0.574 \mathrm{~b}-\mathrm{i}$ & $0.499 \mathrm{~b}-1$ & $0.468 \mathrm{c}-1$ \\
Mk3 & $0.945 \mathrm{a}$ & $0.400 \mathrm{e}-1$ & 0.2471 & $0.293 \mathrm{i}-1$ \\
Mk5 & $0.653 \mathrm{~b}-\mathrm{e}$ & $0.752 \mathrm{ab}$ & $0.374 \mathrm{e}-1$ & $0.353 \mathrm{f}-1$ \\
Mk8 & $0.742 \mathrm{a}-\mathrm{c}$ & $0.467 \mathrm{c}-1$ & $0.447 \mathrm{~d}-1$ & $0.438 \mathrm{~d}-1$ \\
Mk10 & $0.543 \mathrm{~b}-\mathrm{k}$ & $0.293 \mathrm{i}-1$ & $0.325 \mathrm{~g}-1$ & $0.288 \mathrm{j}-1$ \\
Mk13 & $0.548 \mathrm{~b}-\mathrm{k}$ & $0.595 \mathrm{~b}-\mathrm{g}$ & $0.277 \mathrm{kl}$ & $0.339 \mathrm{f}-1$ \\
Mk15 & $0.749 \mathrm{ab}$ & $0.370 \mathrm{e}-1$ & $0.491 \mathrm{~b}-1$ & $0.235 \mathrm{l}$ \\
Mk20 & $0.437 \mathrm{~d}-1$ & $0.312 \mathrm{~g}-1$ & $0.639 \mathrm{~b}-\mathrm{e}$ & $0.384 \mathrm{e}-1$ \\
Mk22 & $0.691 \mathrm{a}-\mathrm{d}$ & $0.590 \mathrm{~b}-\mathrm{h}$ & $0.315 \mathrm{~g}-1$ & $0.308 \mathrm{~h}-1$ \\
Mk25 & $0.935 \mathrm{a}$ & $0.565 \mathrm{~b}-\mathrm{j}$ & $0.577 \mathrm{~b}-\mathrm{i}$ & $0.487 \mathrm{~b}-1$ \\
LSD value $(\mathrm{p} \leq 0.05)$ & 0.2298 & & \\
\hline
\end{tabular}

Means sharing same letters are statistically at par at $5 \%$ level of probability. $n=3$. 
Table 4 - Response of rhizobial strain to different levels of salinity after 3 days of incubation.

\begin{tabular}{lcccc}
\hline Strain & \multicolumn{5}{c}{ Optical density at $540 \mathrm{~nm}$} \\
\cline { 2 - 5 } & $1.61 \mathrm{dS} \mathrm{m}^{-1}$ & $4 \mathrm{dS} \mathrm{m}^{-1}$ & $8 \mathrm{dS} \mathrm{m}^{-1}$ & $12 \mathrm{dS} \mathrm{m}^{-1}$ \\
\hline M1 & $0.894 \mathrm{bc}$ & $0.604 \mathrm{~d}-\mathrm{h}$ & $0.411 \mathrm{e}-\mathrm{k}$ & $0.343 \mathrm{~h}-\mathrm{m}$ \\
M2 & $0.453 \mathrm{e}-\mathrm{k}$ & $0.625 \mathrm{~d}-\mathrm{f}$ & $0.373 \mathrm{e}-1$ & $0.354 \mathrm{~g}-1$ \\
M3 & $0.808 \mathrm{~cd}$ & $0.632 \mathrm{de}$ & $0.379 \mathrm{e}-1$ & $0.293 \mathrm{j}-\mathrm{m}$ \\
M4 & $0.610 \mathrm{~d}-\mathrm{g}$ & $0.502 \mathrm{e}-\mathrm{k}$ & $0.401 \mathrm{e}-\mathrm{k}$ & $0.263 \mathrm{k}-\mathrm{m}$ \\
M5 & $0.582 \mathrm{~d}-\mathrm{i}$ & $0.434 \mathrm{e}-\mathrm{k}$ & $0.440 \mathrm{e}-\mathrm{k}$ & $0.299 \mathrm{j}-\mathrm{m}$ \\
M6 & $0.998 \mathrm{a}-\mathrm{c}$ & $0.639 \mathrm{de}$ & $0.465 \mathrm{e}-\mathrm{k}$ & $0.359 \mathrm{f}-1$ \\
M7 & $0.541 \mathrm{e}-\mathrm{j}$ & $0.234 \mathrm{k}-\mathrm{m}$ & $0.301 \mathrm{j}-\mathrm{m}$ & $0.273 \mathrm{j}-\mathrm{m}$ \\
M8 & $1.130 \mathrm{ab}$ & $0.633 \mathrm{de}$ & $0.331 \mathrm{i}-\mathrm{m}$ & $0.284 \mathrm{j}-\mathrm{m}$ \\
M9 & $1.066 \mathrm{ab}$ & $0.809 \mathrm{~cd}$ & $0.443 \mathrm{e}-\mathrm{k}$ & $0.418 \mathrm{e}-\mathrm{k}$ \\
M10 & $1.179 \mathrm{a}$ & $0.249 \mathrm{k}-\mathrm{m}$ & $0.082 \mathrm{~m}$ & $0.115 \mathrm{~lm}$ \\
LSD value $(\mathrm{p} \leq 0.05)$ & 0.2180 & & \\
\hline
\end{tabular}

Means sharing same letters are statistically at par at $5 \%$ level of probability. $n=3$.

Table 5 - Effect of rhizobacterial inoculation on total dry matter and salt tolerance index of mung bean seedlings under salt-stressed axenic conditions.

\begin{tabular}{|c|c|c|c|c|c|}
\hline \multirow[t]{2}{*}{ Treatment } & Control & $4 \mathrm{dS} \mathrm{m}^{-1}$ & $6 \mathrm{dS} \mathrm{m}^{-1}$ & $4 \mathrm{dS} \mathrm{m}^{-1}$ & $6 \mathrm{dS} \mathrm{m}^{-1}$ \\
\hline & \multicolumn{3}{|c|}{ Total dry matter $\left(\right.$ g plant $\left.^{-1}\right)$} & \multicolumn{2}{|c|}{ Salt tolerance index } \\
\hline Control & $0.037 \mathrm{a}-\mathrm{g}$ & $0.024 \mathrm{~d}-\mathrm{h}$ & $0.014 \mathrm{~h}$ & $0.66 \mathrm{c}$ & $0.40 \mathrm{e}$ \\
\hline Mk1 & $0.051 \mathrm{a}$ & $0.043 \mathrm{a}-\mathrm{d}$ & $0.034 \mathrm{a}-\mathrm{g}$ & $1.18 \mathrm{a}$ & $0.93 \mathrm{a}$ \\
\hline Mk3 & $0.042 \mathrm{a}-\mathrm{f}$ & $0.038 \mathrm{a}-\mathrm{g}$ & $0.023 \mathrm{~d}-\mathrm{h}$ & $1.04 \mathrm{ab}$ & $0.64 \mathrm{~cd}$ \\
\hline Mk5 & $0.046 \mathrm{a}-\mathrm{c}$ & $0.037 \mathrm{a}-\mathrm{g}$ & $0.023 \mathrm{e}-\mathrm{h}$ & $1.02 \mathrm{ab}$ & $0.64 \mathrm{~cd}$ \\
\hline Mk8 & $0.044 \mathrm{a}-\mathrm{d}$ & $0.039 \mathrm{a}-\mathrm{f}$ & $0.028 \mathrm{~b}-\mathrm{h}$ & $1.07 \mathrm{ab}$ & $0.77 \mathrm{a}-\mathrm{c}$ \\
\hline Mk10 & $0.046 \mathrm{ab}$ & $0.033 \mathrm{a}-\mathrm{h}$ & $0.022 \mathrm{f}-\mathrm{h}$ & $0.92 \mathrm{~b}$ & $0.61 \mathrm{~cd}$ \\
\hline Mk13 & $0.042 \mathrm{a}-\mathrm{f}$ & $0.037 \mathrm{a}-\mathrm{g}$ & $0.026 \mathrm{c}-\mathrm{h}$ & $1.03 \mathrm{ab}$ & $0.71 \mathrm{bc}$ \\
\hline Mk15 & $0.044 \mathrm{a}-\mathrm{d}$ & $0.034 \mathrm{a}-\mathrm{h}$ & $0.025 \mathrm{~d}-\mathrm{h}$ & $0.92 \mathrm{a}$ & $0.70 \mathrm{~cd}$ \\
\hline $\mathrm{Mk} 20$ & $0.051 \mathrm{a}$ & $0.043 \mathrm{a}-\mathrm{e}$ & $0.032 \mathrm{a}-\mathrm{h}$ & $1.17 \mathrm{a}$ & $0.87 \mathrm{ab}$ \\
\hline Mk22 & 0.043 a-e & $0.039 \mathrm{a}-\mathrm{f}$ & $0.019 \mathrm{gh}$ & $1.07 \mathrm{ab}$ & $0.53 \mathrm{de}$ \\
\hline Mk25 & $0.050 \mathrm{a}$ & $0.040 \mathrm{a}-\mathrm{f}$ & $0.033 \mathrm{a}-\mathrm{h}$ & $1.10 \mathrm{ab}$ & $0.91 \mathrm{a}$ \\
\hline LSD value & 0.0163 & & & 0.1561 & \\
\hline
\end{tabular}

Means sharing same letters are statistically at par at $5 \%$ level of probability. $n=3$.

ever, the effect of the strain M6 was significant in comparison with respective un-inoculated control.

Inoculation with rhizobacteria and Rhizobium had very promising results for improving the salt tolerance index at all salinity levels. Maximum increase in salt tolerance index was observed with rhizobacterial strain Mk1, both at low as well as high salinity level (Table 5 However, in case of Rhizobium inoculation, maximum increase in salt tolerance index (1.6 fold) over the un-inoculated control was observed with Rhizobium strain M6, at $4 \mathrm{dS} \mathrm{m}^{-1}$, while M6 gave most promising results at $6 \mathrm{dS} \mathrm{m}^{-1}$ (Table 6).
Table 6 - Effect of rhizobial inoculation on total dry matter and salt tolerance index of mung bean seedlings under salt-stressed axenic conditions.

\begin{tabular}{lccccccc}
\hline \multirow{2}{*}{ Treatment } & Control & $4 \mathrm{dS} \mathrm{m}^{-1}$ & $6 \mathrm{dS} \mathrm{m}^{-1}$ & & $4 \mathrm{dS} \mathrm{m}^{-1}$ & $6 \mathrm{dS} \mathrm{m}^{-1}$ \\
\cline { 2 - 3 } \cline { 7 - 8 } & \multicolumn{2}{c}{ Total dry matter $\left(\mathrm{g} \mathrm{plant}^{-1}\right)$} & & \multicolumn{2}{c}{ Salt tolerance index } \\
\hline Control & $0.0301-\mathrm{o}$ & $0.0291 \mathrm{l}-\mathrm{o}$ & $0.013 \mathrm{o}$ & & $0.99 \mathrm{f}$ & $0.43 \mathrm{c}$ \\
M1 & $0.072 \mathrm{a}-\mathrm{e}$ & $0.057 \mathrm{~d}-\mathrm{i}$ & $0.028 \mathrm{~m}-\mathrm{o}$ & & $1.95 \mathrm{~cd}$ & $0.96 \mathrm{ab}$ \\
M2 & $0.081 \mathrm{ab}$ & $0.028 \mathrm{~m}-\mathrm{o}$ & $0.013 \mathrm{o}$ & & $0.93 \mathrm{f}$ & $0.44 \mathrm{c}$ \\
M3 & $0.068 \mathrm{~b}-\mathrm{g}$ & $0.068 \mathrm{~b}-\mathrm{f}$ & $0.028 \mathrm{~m}-\mathrm{o}$ & & $2.32 \mathrm{~b}$ & $0.96 \mathrm{ab}$ \\
M4 & $0.080 \mathrm{ab}$ & $0.053 \mathrm{e}-\mathrm{j}$ & $0.025 \mathrm{~m}-\mathrm{o}$ & & $1.79 \mathrm{de}$ & $0.86 \mathrm{~b}$ \\
M5 & $0.064 \mathrm{~b}-\mathrm{h}$ & $0.059 \mathrm{c}-\mathrm{i}$ & $0.028 \mathrm{~m}-\mathrm{o}$ & & $1.98 \mathrm{~cd}$ & $0.95 \mathrm{ab}$ \\
M6 & $0.088 \mathrm{a}$ & $0.077 \mathrm{a}-\mathrm{c}$ & $0.036 \mathrm{j}-\mathrm{n}$ & & $2.61 \mathrm{a}$ & $1.23 \mathrm{a}$ \\
M7 & $0.049 \mathrm{f}-\mathrm{k}$ & $0.058 \mathrm{c}-\mathrm{i}$ & $0.026 \mathrm{~m}-\mathrm{o}$ & & $1.98 \mathrm{~cd}$ & $0.90 \mathrm{~b}$ \\
M8 & $0.049 \mathrm{~h}-\mathrm{k}$ & $0.047 \mathrm{~h}-1$ & $0.022 \mathrm{no}$ & & $1.58 \mathrm{e}$ & $0.74 \mathrm{~b}$ \\
M9 & $0.076 \mathrm{a}-\mathrm{d}$ & $0.066 \mathrm{~b}-\mathrm{h}$ & $0.031 \mathrm{k}-\mathrm{o}$ & & $2.24 \mathrm{bc}$ & $1.04 \mathrm{ab}$ \\
M10 & $0.040 \mathrm{i}-\mathrm{n}$ & $0.045 \mathrm{i}-\mathrm{m}$ & $0.022 \mathrm{no}$ & & $1.52 \mathrm{e}$ & $0.75 \mathrm{~b}$ \\
LSD value & 0.0163 & & & & 0.2850 & \\
\hline
\end{tabular}

Means sharing same letters are statistically at par at $5 \%$ level of probability. $n=3$.

\section{Screening of effective combinations of Rhizobium and Pseudomonas containing ACC-deaminase for inducing osmotic stress tolerance}

The most effective strains in the above trials were screened for their combined effect to improve salt tolerance in mung bean seedlings under salt-affected axenic conditions. The results showed that co-inoculation of Rhizobium and Pseudomonas strains containing ACC-deaminase activity significantly reduced the effect of salinity on total dry matter and salt tolerance index of mung bean seedlings.

It was revealed from the data (Figure 1) that co-inoculation with Rhizobium and Pseudomonas strains containing ACC-deaminase improved the total dry matter of mung bean seedlings which otherwise was decreased by salinity. At $6 \mathrm{dS} \mathrm{m}^{-1}$, all the combinations showed significant increase in total dry matter compared with respective un-inoculated control and the maximum increase ( 2.2 fold) was observed by the combination Mk25 x M6. At $4 \mathrm{dS} \mathrm{m}^{-1}$, maximum increase in total dry matter (1.2 fold) over respective un-inoculated control was observed with combination Mk20 x M6 followed by 1.18 fold increase in total dry matter over the un-inoculated control with the combination Mk25 x M9.

The salt tolerance index of mung bean seedlings (Figure 2) was improved due to co-inoculation with Rhizobium and Pseudomonas strains containing ACC-deaminase. At $6 \mathrm{dS} \mathrm{m}^{-1}$, increase in salt tolerance index due to co-inoculation ranged from 1.0 to 2.2 fold over respective un-inoculated control. Maximum increase in salt tolerance index ( 2.2 fold) was observed by the combination Mk $25 \times$ M6. At $4 \mathrm{dS} \mathrm{m}^{-1}$, increase in salt tolerance index due to co-inoculation was also significantly higher than respective un-ino- 


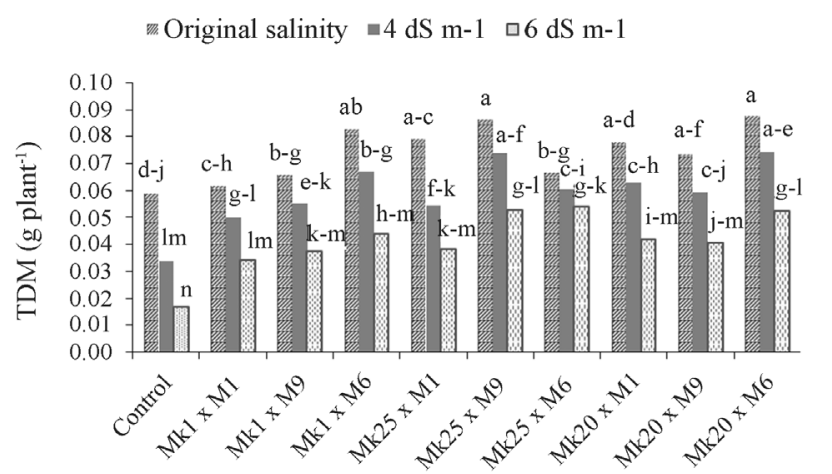

Co-inoculation

Figure 1 - Effect of co-inoculation of Rhizobium and Pseudomonas strains on total dry matter of mung bean seedlings under salt-stressed axenic conditions. Bars sharing same letters are statistically at par at 5\% level of probability. $\mathrm{n}=3$. Mk1, Pseudomonas syringae; Mk20, Pseudomonas fluorescens; Mk25, Pseudomonas fluorescens Biotype G; M1, M2, M3, Rhizobium phaseoli.

$\because 4 \mathrm{dS} \mathrm{m}-1 \square 6 \mathrm{dS} \mathrm{m}-1$

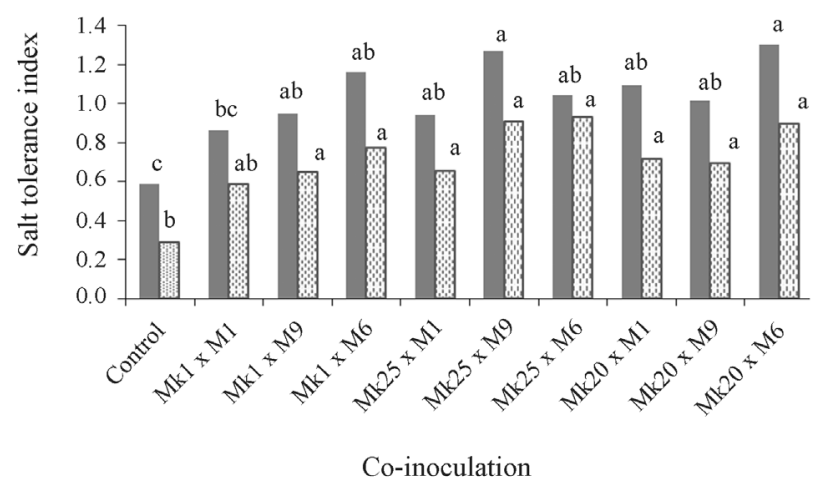

Figure 2 - Effect of co-inoculation of Rhizobium and Pseudomonas strains on salt tolerance index of mung bean seedlings under salt-stressed axenic conditions. Bars sharing same letters are statistically at par at 5\% level of probability. $\mathrm{n}=3$. Mk1, Pseudomonas syringae; Mk20, Pseudomonas fluorescens; Mk25, Pseudomonas fluorescens Biotype G; M1, M2, M3, Rhizobium phaseoli.

culated control. Maximum increase in salt tolerance index (1.2 fold) over un-inoculated control was observed with co-inoculated combination Mk20 x M6.

\section{Discussion}

Some PGPR are capable of lowering stress-induced ethylene levels through an enzyme ACC-deaminase (Zahir et al., 2010). This results in better growth and nodulation in legumes. It is very likely that these bacterial strains could be used to improve plant growth in stressed conditions. In the present study, it was observed that all the rhizobacterial strains possess ACC-deaminase activity as evident from the results of ACC metabolism assay. When grown on ACC, all the strains showed growth but variable cell den- sity was observed. It means these strains have variability in their efficiency to utilize ACC as sole source of nitrogen. This difference in ACC utilization rate by these strains might be due to difference in their ACC-deaminase activity. Some PGPR strains contain an enzyme ACC-deaminase which cleaves the ACC; the immediate precursor of ethylene into ammonia and $\alpha$-ketobutyrate (Glick et al., 1998) and use the released ammonia for their metabolism.

Indole acetic acid is produced by many microbes including PGPR which is an important plant growth regulator. Therefore, there is a close interaction between auxin producing PGPR and plants (Malhotra and Srivastava, 2006; Anjum et al., 2011). In our laboratory study, it was observed that all rhizobacterial strains have the ability to produce auxin but with different efficacy and this auxin production was increased by the addition of L-TRP. The difference in auxin producing ability has also been reported by Fuentes-Ramirez et al. (Fuentes-Ramirez et al., 1993). Increased auxin production by different bacterial strains in the presence of L-TRP has also been reported by De and Basu (1996).

In our study, it was observed that growth of Rhizobium and rhizobacterial strains was adversely affected by salinity. Data showed that Rhizobium growth was optimum under normal conditions but under salt-stressed conditions the strains varied in their growth. Some strains showed more growth even at higher concentrations. Variable ability of bacterial strains to tolerate the salt stress has been reported by Lloret et al. (1995). They reported that some salt tolerant Rhizobium strains can grow at $\mathrm{NaCl}$ concentration up to $500 \mathrm{mM}$. Higher salt tolerance by bacterial strains was also reported by Mensah et al. (2006) and Sgroy et al. (2009).

Higher seedling biomass may increase salt tolerance index of plants thus making the plant better withstand salinity stress. In the present study, salinity significantly reduced the total dry matter and salt tolerance index of mung bean plants under axenic conditions. This might be due to the effect of salinity on plant metabolic and physiological processes or it might be due to the use of most part of energy in making osmotic adjustments by the plant thus decreasing plant growth and total dry matter (Munns and Termaat, 1986).

In our study, inoculation/co-inoculation with Rhizobium and auxin producing Pseudomonas containing ACC-deaminase improved the total dry matter and salt tolerance index of mung bean plants. It might be due to the reduction of adverse effects of stress-induced ethylene on plant physiology. It has been reported that inoculation/coinoculation improved the transpiration rate and other physiological processes (Vivas et al., 2003; Gaballah and Gomaa, 2005; Zahir et al., 2009), thus reducing the effect of salinity on plant growth leading to increased total dry matter and salt tolerance index. This might also be due to reduction in ethylene production due to inoculation/co-ino- 
culation with Rhizobium and PGPR containing ACC-deaminase thus reducing the inhibitory effect of ethylene on root growth leading to more proliferation of roots. The competency of co-inoculation for reducing the effect of salinity due to reduction in ethylene level through ACCdeaminase activity has been proved by conducting the classical triple response assay (Ahmad et al., 2011).

Auxins are produced in excess amounts by the plants subjected to stress (Vaidyanathan et al., 1999; Yurekli et al., 2004) as a plant metabolic strategy to cope with the stressed conditions by shortening the life cycle (Yurekli et al., 2004). This is an adaptive mechanism in plants. But the production of IAA in plants requires an additional amount of energy along with other normal plant metabolic processes. This additional energy use in auxin production reduces the plant metabolism thus decreasing plant growth. So, inoculation with auxin producing PGPR may improve the plant growth (Zahir et al., 2010) thus decreasing the energy requirements. However, inoculation of plants under stress with PGPR that have dual character i.e. auxin production as well as ACC-deaminase activity might have decreased the stress-induced ethylene production as additional amount of IAA produced by these bacteria might be taken up by plants which activates the enzyme ACC synthase thus more ACC production. This ACC may come out due to concentration gradient and induce the enzyme ACC-deaminase in the PGPR which cleaves the ACC into ammonia and $\alpha$-keto butyrate (Glick et al., 1998) thus lowers the ethylene production and improves the plant growth (Zahir et al., 2008).

The strains varied in their ability to reduce the effect of salinity on plant growth and the maximum response was observed when Pseudomonas fluorescens (Mk20) was co-inoculated with Rhizobium phaseoli. It is very likely that PGPR strains vary in their ACC deaminase ability along with some other characters (Ahmad et al., 2011) that contributed differently for growth promotion. Similarly, it was reported in the previous findings that strains differ in their ability to promote plant growth due to difference in ACC deaminase activity (Shaharoona et al., 2006; Nadeem et al., 2007, 2009). This difference may also be due to the presence of other growth promoting characters, in addition to ACC-deaminase activity (Ahmad et al., 2011).

Our results imply that combined application of Rhizobium and Pseudomonas strains improved the osmotic stress tolerance in mung bean seedlings under axenic conditions. However, this approach could be explored as an effective strategy to improve salt tolerance index in mung bean under pot and field conditions.

\section{Acknowledgement}

We are highly thankful to Higher Education Commission, Pakistan for providing the financial support to complete this research project.

\section{References}

Ahmad M, Zahir ZA, Asghar HN, Asghar M (2011) Inducing salt tolerance in mung bean through co-inoculation with Rhizobium and PGPR containing ACC-deaminase. Can J Microbiol 57:578-589.

Anjum MA, Zahir ZA, Arshad M, Ashraf M (2011) Isolation and screening of rhizobia for auxin biosynthesis and growth promotion of mung bean (Vigna radiata L.) seedlings under axenic conditions. Soil Environ 30:18-26.

Azooz MM, Shaddad MA, Abdel-Latef AA (2004) Leaf growth and $\mathrm{K}^{+} / \mathrm{Na}^{+}$ratio as an indication of the salt tolerance of three sorghum cultivars grown under salinity stress and IAA treatment. Acta Agron Hungarica 52:287-296.

Barea J, Pozo MJ, Azcon R, Azcon-Aguilar C (2005) Microbial co-operation in the rhizosphere. J Exp Bot 56:1761-1778.

Belimov AA, Dodd IC, Hontzeas N, Theobald JC, Safronova VI, Davies WJ (2009) Rhizosphere bacteria containing ACCdeaminase increase yield of plants grown in drying soil via both local and systemic hormone signaling. New Phytologist 181:413-423.

Belimov AA, Dodd IC, Safronova VI, Davies WJ (2009) ACCdeaminase-containing rhizobacteria improve vegetative development and yield of potato plants grown under waterlimited conditions. Aspects Appl Biol 98:163-169.

Chartzoulakis K, Loupassaki M, Bertaki M, Androulakis I (2002) Effects of $\mathrm{NaCl}$ salinity on growth, ion content and $\mathrm{CO}_{2}$ assimilation rate of six olive cultivars. Sci Hort 96:235-247.

Dashti N, Zhang F, Hynes R, Smith DL (1997) Application of plant growth-promoting rhizobacteria to soybean (Glycine $\max$ L. Merr.) increases protein and dry matter yield under short season conditions. Plant Soil 188:33-41.

De PS, Basu PS (1996) Content of different phytohormones and indole acetic acid metabolism in root nodules of Derris scandens. J Basic Microbiol 36:299-304.

Derylo M, Skorupska A (1993) Enhancement of symbiotic nitrogen fixation by vitamin-secreting fluorescent Pseudomonas. Plant Soil 54:211-217.

Duncan DB (1955) Multiple range and multiple F-test. Biometrics 11:1-42.

Fahraeus G (1957) The infection of clover root hairs by nodule bacteria, studied by a simple glass slide technique. J Gen Microbiol 16:374-381.

Fuentes-Ramirez LE, Jimenez-Salgado T, Abarco-Ocampo IR, Caballero-Mellado (1993) Acetobacter diazotrophicus, an Indole-acetic acid producing bacterium isolated from sugarcane cultivars of Mexico. Plant Soil 154:145-150.

Gaballah MS, Gomaa AM (2005) Interactive effect of Rhizobium inoculation, sodium benzoate and salinity on performance and oxidative stress in two faba bean varieties. Int J Agri Biol 7:495-498.

Glick BR, Penrose DM, Li J (1998) A model for the lowering of plant ethylene concentrations by plant growth promoting rhizobacteria. J Theor Biol 190:63-68.

Gull M, Hafeez FY, Saleem M (2004) Phosphorus uptake and growth promotion of chickpea by co-inoculation of mineral phosphate solubilising bacteria and a mixed rhizobial culture. Aust J Exp Agric 44:623-628.

Hafeez FY, Aslam Z, Malik KA (1988) Effect of salinity and inoculation on growth, nitrogen fixation and nutrient uptake of Vigna radiata (L.) Wilczek. Plant Soil 106:3-8. 
Jacobson CB, Pasternak JJ, Glick BR (1994) Partial purification and characterization of 1-aminocyclopropane-1-carboxylate deaminase from the plant growth promoting rhizobacterium Pseudomonas putida GR12-2. Can J Microbiol 40:10191025.

Lloret J, Bolaños L, Lucas MM, Peart JM, Brewin NJ, Bonilla I, Rivilla R (1995) Ionic stress and osmotic pressure induce different alterations in the lipopolysaccharide of a Rhizobium meliloti strain. Appl Environ Microbiol 61:3701-3704.

Madhaiyan M, Poonguzhali S, Sa TM (2007) Characterization of 1-Aminocyclopropane-1-carboxylate deaminase (ACC) deaminase containing Methylobacterium oryzae and interactions with auxins and ACC regulation of ethylene in canola (Brassica campestris). Planta 226:867-876.

Malhotra M, Srivastava S (2006) Targeted engineering of Azospirillum brasiliense with indole acetamide pathway for indole acetic acid over-expression. Can J Microbiol 52:1078-1084.

Mayak S, Tirosh T, Glick BR (1999) Effect of wild-type and mutant plant growth promoting rhizobacteria on the rooting of mung bean cuttings. J Plant Growth Regul 18:49-53.

Mensah JK, Esumeh F, Lyamu M, Omoifu C (2006) Effect of different salt concentrations and $\mathrm{pH}$ on growth of Rhizobium sp. and a cowpea-Rhizobium association. Am-Eur. J Agric Environ Sci 1:198-202.

Munns R, Termaat A (1986) Whole-plant responses to salinity. Aust J Plant Physiol 13:143-160.

Nadeem SM, Zahir ZA, Naveed M, Arshad M (2007) Preliminary investigations on inducing salt tolerance in maize through inoculation with rhizobacteria containing ACC deaminase activity. Can J Microbiol 53:1141-1149.

Nadeem SM, Zahir ZA, Naveed M, Arshad M (2009) Rhizobacteria containing ACC deaminase confer salt tolerance in maize grown on salt affected soils. Can J Microbiol 55:1302-1309.

Parida AK, Das AB (2005) Salt tolerance and salinity effects on plants: a review. Ecotoxicol. Environ Saf 60:324-349.

Sarwar M, Arshad M, Martens DA, Frankenberger WT Jr (1992) Tryptophan dependent biosynthesis of auxins in soil. Plant Soil 147:207-215.

Sgroy V, Cassan F, Masciarelli O, Del Papa MF, Lagares A, Luna V (2009) Isolation and characterization of endophytic plant growth-promoting (PGPB) or stress homeostasis-regulating
(PSHB) bacteria associated to the halophyte Prosopis strombulifera. Appl Microbiol Biotechnol 85:371-381.

Shaharoona B, Arshad M, Zahir ZA (2006) Effect of plant growth promoting rhizobacteria containing ACC-deaminase on maize (Zea mays L.) growth under axenic conditions and on nodulation in mung bean (Vigna radiata L.). Lett Appl Microbiol 42:155-159.

Shetty G, Hetrick D, Schwat P (1995) Effectes of mycorrhizal fertilizers amendments on zinc tolerance of plants. Environ Pollution 88:307-314.

Steel RGD, Torrie JH, Dicky DA (1997) Principles and procedures of statistics - A biometrical approach. $3^{\text {rd }}$ edition. McGraw Hill Book International Co, Singapore.

Tahir M, Arshad M, Naveed M, Zahir ZA, Shaharoona B, Ahmad $R$ (2006) Enrichment of recycled organic waste with $N$ fertilizer and PGPR containing ACC-deaminase for improving growth and yield of tomato. Soil Environ 25:105-112.

Vaidyanathan R, Kuruvilla S, Thomas G (1999) Characterization and expression pattern of an abscisic acid and osmotic stress responsive gene from rice. Plant Sci 140:21-30.

Vivas A, Marulanda A, Ruiz-Lozano JM, Barea JM, Azcón R (2003) Influence of a Bacillus sp. on physiological activities of two arbuscular mycorrhizal fungi and on plant responses to PEG-induced drought stress. Mycorrhiza 13:249-256.

Woldeyohannes WH, Dasilva MC, Gueye M (2007) Nodulation and nitrogen fixation of Stylosanthes hamata in response to induced drought stress. Arid Land Res Manage 21:157-163.

Yurekli F, Porgali ZB, Turkan I (2004) Variations in abscisic acid, indole-3-acetic acid, gibberellic acid and zeatin concentrations in two bean species subjected to salt stress. Acta Biologica Cracoviensia Series Botanica 46:201-212.

Zahir ZA, Munir A, Asghar HN, Shahroona B, Arshad M (2008) Effectiveness of rhizobacteria containing ACC-deaminase for growth promotion of peas (Pisum sativum) under drought conditions. J Microbiol Biotechnol 18:958-963.

Zahir ZA, Ghani U, Naveed M, Nadeem SM, Asghar HN (2009) Comparative effectiveness of Pseudomonas and Serratia sp. containing ACC-deaminase for improving growth and yield of wheat (Triticum aestivum L.) under salt-stressed conditions. Arch Microbiol 191:415-424.

Zahir ZA, Shah MK, Naveed M, Akhter MJ (2010) Substratedependent auxin production by Rhizobium phaseoli improves the growth and yield of Vigna radiata $\mathrm{L}$. under salt stress conditions. J Microbiol Biotechnol 20:1288-1294.

All the content of the journal, except where otherwise noted, is licensed under a Creative Commons License CC BY-NC. 